\title{
Is Field of Study or Location Associated with College Students' Snacking Patterns?
}

\author{
Laura H. McArthur, ${ }^{1}$ Donald Holbert, ${ }^{2}$ and William Forsythe ${ }^{3}$ \\ ${ }^{1}$ Department of Dietetics, Fashion Merchandising \& Hospitality, Western Illinois University, Macomb, IL 61455, USA \\ ${ }^{2}$ Department of Biostatistics, East Carolina University, Greenville, NC 27858, USA \\ ${ }^{3}$ Department of Nutrition and Dietetics, East Carolina University, Greenville, NC 27858, USA
}

Correspondence should be addressed to Donald Holbert, holbertd@ecu.edu

Received 12 July 2011; Revised 14 September 2011; Accepted 20 November 2011

Academic Editor: Ruth H. Striegel-Moore

Copyright (C) 2012 Laura H. McArthur et al. This is an open access article distributed under the Creative Commons Attribution License, which permits unrestricted use, distribution, and reproduction in any medium, provided the original work is properly cited.

Objective. To compare on- and off-campus snacking patterns among college students pursuing degrees in health-related fields (HRFs) and nonhealth-related fields (NHRFs). Materials and Methods. Snack frequency questionnaire, scales measuring barriers, self-efficacy, and stage of change for healthy snacking, and a snack knowledge test (SKT). Participants. 513 students, $46 \%$ HRFs, and $54 \%$ NHRFs. The students' mean \pm SD BMI was $24.1 \pm 4.3 \mathrm{~kg} / \mathrm{m}^{2}$ (range 14.6 to 43.8 ), and $32.2 \%$ were overweight/obese. Results. Softdrinks (on-campus), lowfat milk (off-campus), and sports drinks were popular among HRFs and NHRFs. Cost and availability were barriers to healthy snacking, students felt least confident to choose healthy snacks when emotionally upset, and $75 \%(65 \%)$ of HRFs (NHRFs) self-classified in the action stage of change for healthy snacking. The HRFs scored higher on the SKT. Conclusions. Neither location nor field of study strongly influenced snacking patterns, which featured few high-fiber foods.

\section{Introduction}

The United States is currently experiencing an epidemic of overweight [1], defined as a body mass index (BMI) between 25.0 and $29.9 \mathrm{~kg} / \mathrm{m}^{2}$, and obesity, defined as a BMI of $30.0 \mathrm{~kg} / \mathrm{m}^{2}$ or greater [2]. Among the groups showing an increased incidence of excess adiposity are college students [3]. Currently, there are an estimated 16.6 million young people aged 18 to 24 enrolled in US colleges and universities, [4] and it is estimated that $26 \%$ of Caucasian and $50 \%$ of African American college students are either overweight or obese [3]. Additionally, an estimated 33\% of US college students have a total cholesterol level above $200 \mathrm{mg} / \mathrm{dL}$, about $20 \%$ have HDL cholesterol concentrations below $40 \mathrm{mg} / \mathrm{dL}$, and another $15 \%$ to $21 \%$ have prehypertension [5]. These trends are of concern to health care providers because ample clinical and epidemiological evidence links BMIs of 25.0 or greater to hypertension, heart disease, type 2 diabetes mellitus, strokes, and some types of cancers [6]. Although these chronic diseases are generally manifested in older adults, Skelton and coworkers [7] and Shaw [8] noted that these conditions can originate during childhood and adolescence. Moreover, several authors [7-9] have observed that these developmental periods may be critical for weight gain. Thus, an objective of the federally sponsored Healthy People 2010 initiative [10] was to increase the proportion of college students who are at a healthy weight (BMI between 18.5 and 24.9), and the US Surgeon General's Call to Action [11] proposed that more policies and interventions promoting healthy dietary and physical activity habits be implemented to meet this objective.

Several investigators [12-15] have reported that snacks, defined as unstructured eating occasions between meals [16] contribute significantly to the daily caloric intake of adolescents and young adults, and that frequent consumption of energy-dense snack foods may be contributing to the increasing occurrence of overweight/obesity among collegeaged individuals. This argument is strengthened by data documenting the widespread availability and large sales volume of energy-dense snack foods. For example, Farley and co-workers [12] conducted systematic observations of 1082 retail stores in 19 US cities to determine the availability of 
six categories of higher-calorie (i.e., high-fat, sugary) snack foods. They found that these products were available in $41 \%$ of the stores; the most common products were candy (33\%), sweetened beverages (20\%), and salty snacks (17\%). Moreover, snack foods were sold in $96 \%$ of pharmacies, $94 \%$ of gasoline stations, $22 \%$ of furniture stores, $16 \%$ of apparel stores, and $29 \%$ to $65 \%$ of other types of stores. Additionally, Pineda and Kleiner [16] reported a significant increase in the consumption of candy, soft drinks, fruit drinks, French fries, cheeseburgers, and pizza by adolescents and young adults over the past 30 years. In this regard, Zenk and Powell [17] reported that US adolescents aged 12 to 19 spent approximately $\$ 159$ billion on food, candy, and soft drinks in 2005 alone. Additionally, the snack industry publication Vending Times [18] reported that the sales of cold beverages and snack foods combined totaled $\$ 34.3$ billion or $73 \%$ of vending machine sales in 2006. The findings reported by Nelson and Story [13] for US college students reflect these sales and consumption trends. These investigators inventoried the foods and beverages found in the dormitory rooms of 100 college students and reported that more than $70 \%$ of the students had salty snacks, desserts or candy, and sugar-sweetened beverages, while fewer students had lowercalorie beverages, fruits and vegetables, dairy products, tea/coffee, and pure fruit/vegetable juice. They also noted that the mean number of food and beverage items per student was 47 (range zero to 208), and that the average number of calories per dormitory room was 22,888 .

The Transtheoretical Model (TM), originally used by Prochaska and Di Clemente [19] as a conceptual framework for the study of addictive behaviors, has since been used successful to identify correlates of healthy eating for use in clinical and educational settings [20-23]. In its expanded form, the TM consists of four dimensions, that is, the stages of change, the processes of change, situational self-efficacy, and decisional balance. The stages of change represent the temporal, motivational, and consistency constructs of behavior change. These stages are precontemplation (no thought is given to adopting a healthy behavior within the next six months), contemplation (serious consideration is given to adopting a healthy behavior within the next six months), preparation (the decision is made to adopt a healthy behavior within the next 30 days), action (the healthy behavior has been practiced for six months or less, and it requires considerable effort to maintain), maintenance (the healthy behavior has been practiced for longer than six months, and it requires less effort to maintain), and termination (the healthy behavior has become automatic).

The TM hypothesizes that individuals can transition from the preaction (precontemplation, contemplation, and preparation) to the action (action, maintenance, and termination) stages through cognitive and behavioral processes of change. The cognitive processes focus on gathering information about the unhealthy behavior, leading to an attitude change conducive to a positive behavior change. The behavioral processes involve adopting strategies that facilitate replacing an unhealthy with a healthy behavior. The situational self-efficacy dimension measures the degree of confidence to undertake a healthy behavior under different circumstances, and the decisional balance component examines perceived barriers and benefits to adopting a healthy behavior.

College students pursuing academic degrees in healthrelated disciplines (e.g., nursing science, dietetics, wellness, health education, community health, etc.) are likely to engage in counseling future clients about healthy lifestyle behaviors, including dietary strategies for long-term health maintenance. It would, therefore, be helpful for educators in these and other health-related disciplines to monitor the dietary habits of these students, including their snack selections, to determine whether they are setting the stage for modeling a positive or a negative dietary behavior before beginning their professional careers. Furthermore, since the snack choices available to college students when spending time on-campus may differ from those available to them when off-campus in terms of variety and nutrient composition, it would be useful to identify their snack choices in the context of place, to examine their degree of consistency in snack selection under different environmental circumstances. Thus, the aims of this study were to (1) compare the on- and off-campus snacking patterns (i.e., snack choices and frequency of consumption) for college students pursuing academic degrees in health-related fields (HRFs, and in other fields (NHRFs), (2) compare these student samples on the psychosocial correlates from the TM, that is, perceived barriers, situational self-efficacy, and stage of change, (3) measure the students' knowledge concerning the nutritional characteristics of healthy snacks, and (4) identify associations between the students' snacking patterns and the psychosocial correlates from the TM. Several authors [2123] have found that health promotion interventions are more effective if they are tailored to the target audience, which requires an assessment of the psychosocial correlates that may hinder the desired dietary change.

\section{Materials and Methods}

2.1. Participants and Recruitment. Convenience sampling was used to recruit male and female undergraduates at hightraffic locations (i.e., student union, residence halls, dining rooms, outside the library) at a southeastern university. Participation was restricted to off-campus residents to increase the likelihood that the students would have access to a variety of off-campus commercial establishments where snack foods could be purchased, in addition to those located on-campus, to facilitate comparisons of on- versus offcampus snacking patterns. Recruitment was accomplished by one female and one male undergraduate student under the supervision of two nutrition professors. Given that offcampus residents frequent the university primarily on week days, recruitment took place on different days of the week (excluding weekends) and at different times of day to obtain a sample that closely reflected the demographics of the offcampus residents enrolled at the University during the time of data collection.

Informed consent was explained in a cover letter attached to each questionnaire, no incentives were offered for participation, and receipt of a completed questionnaire was 
interpreted as obtaining informed consent. Confidentiality of responses was insured by storing the questionnaires in a locked filing cabinet in the office of one of the investigators. This research was approved by the University and Medical Center Institutional Review Board at the study site.

2.2. Survey Questionnaire. Data were collected over a threemonth period using an anonymous, self-administered questionnaire that was completed at the recruitment sites. The students' snack choices and frequency of consumption were assessed using a snack food frequency questionnaire (SFFQ) that was developed by the authors with guidance from the snacking literature [12-18]. This assessment method was used because it is relatively inexpensive to administer and process and requires a relatively low respondent burden [24]. Validity is difficult to establish for all dietary assessment methods, since obtaining the "gold standard" dietary information would involve continuous monitoring of study participants for 24 hours per day [24]. The term snack was defined in the questionnaire as a food or beverage that is consumed between meals [16]. The SFFQ contained 12 higher-calorie snacks (i.e., snacks that are higher in fats, oils, and caloric sweeteners relative to their protein, fiber, and micronutrient content) and their lower-calorie counterparts. Thus, on the SFFQ, snacks were listed as follows: regular ice cream, low-fat/low-sugar ice cream, regular chips, lower-fat chips, regular yogurt, lower-fat/lower-sugar yogurt, regular soft drinks, diet soft drinks, regular cookies, lower-fat/lowersugar cookies, and so forth. Ten additional higher-calorie and seven additional lower-calorie snacks were also included. The higher-calorie and lower-calorie snacks were scrambled throughout the SFFQ rather than listed in pairs to minimize the occurrence of an expectation bias. The columns of the SFFQ were labeled Snack, Location, and How Often Do You Eat This Snack? Next to each snack food under the column labeled Location were the terms Residence and On-Campus, and the students were instructed to estimate how often they consumed each snack at these two locations. The temporal categories listed under the How Often column were Never, Once a month, Two to three times a month, Once a week, Twice a week, Three to four times a week, Five to six times a week, Once a day, Twice a day, and Three or more times a day. The students estimated how often they consumed each snack on- and off-campus by filling in the bubble under the most appropriate column. These SFFQ data do not, however, indicate whether the snacks consumed on- or off-campus were purchased at these locations.

The students rated the perceived importance of 11 potential barriers to healthy snacking on- and off-campus on a five-point scale where 1 meant not at all important and 5 meant very important. Six of the barriers focused on practical concerns, two on awareness of healthy snacks, and three focused on internal cues. These barriers, developed by the authors with guidance from the literature [21-23] had an overall Cronbach's alpha coefficient of 0.85 (average interitem correlation $=0.121$ ) for the off-campus and 0.84 (average interitem correlation $=0.114$ ) for the on-campus locations, respectively.
The students' situational self-efficacy to consume healthy snacks was assessed using modified versions of the subscales developed by Ônpuu and co-workers [21]. The negative/affective subscale (seven items) describes circumstances associated with emotional upset, the positive/social subscale (four items) describes social/celebratory situations, and the difficult/inconvenient subscale (six items) describes circumstances where accessing healthy snacks would be challenging. Each item was rated only once, regardless of where the students snacked, using a five-point scale where 1 meant not at all confident and 5 meant very confident. The Cronbach alpha coefficients for the present sample were 0.90 for the negative/affective, 0.85 for the positive/social, and 0.84 for the difficult/inconvenient subscale. The students' readiness to eat healthy snacks was assessed only once, regardless of where the snacking occurred, using Prochaska's descriptors of the stages of change for adopting a healthy behavior [19]. This framework has been validated in several dietary studies where the aim was to classify participants according to their motivation to adopt a healthy eating behavior [25-28].

The students' knowledge of healthy snacks was measured using a 14-item snack knowledge test (SKT) developed by the authors. The first eight items consisted of a list of nutrient descriptors, and the students circled yes or no to indicate whether the descriptors were characteristic of healthy snacks. These items were followed by six multiplechoice questions that asked the students to identify the snack that possessed the nutrient characteristic specified in the stem of the questions, with each stem followed by three answer choices.

The questionnaire concluded by asking the students to respond to four attitudinal items concerning their snack choices and to provide demographic information. The first attitudinal item asked the students to assess their perceived overall healthfulness of the snacks they typically consumed by circling either mostly unhealthy, some unhealthy/some healthy, or mostly healthy. The second item assessed the extent to which the students agreed with the following statement: "My current snack choices could have an influence on my physical health in the years to come." The response options for this item were arranged along a five-point Likert scale. The students were also asked to indicate the type of influence they thought their current snack choices could have on their physical health in the years to come, by circling either mostly unfavorable, no influence, mostly favorable, or no opinion. Lastly, the students were asked whether they would be interested in learning more about how to choose and prepare healthy snacks, and if so, to circle (from a list of seven sources) their preferred sources for receiving this information. The demographic items elicited information about sex, race/ethnicity, year in school, self-reported height and weight (used to calculate BMI), and field of study.

2.3. Pilot Test. The questionnaire was pilot tested and revised based on input from 20 undergraduates who did not participate in the final study. Accordingly, sports drinks were added to the SFFQ, and the list of potential information sources about healthy snacking was expanded to include 
the campus newspaper and radio station. Face and content validity of all measures were determined by a panel of three nutrition professors experienced at questionnaire design and familiar with the snacking literature and with the psychosocial correlates that were measured.

2.4. Statistical Analyses. Data were analyzed using the Statistical Package for the Social Sciences version 13.1 (SPSS Inc, Chicago, IL, USA) and the Statistical Analysis Systems version 9.1 (SAS Institute, Cary, NC, USA) software packages. Frequency counts, means, and percents were obtained on data from the SFFQ, on the psychosocial correlates, and on attitudinal and demographic items. The ten temporal categories listed on the SFFQ were collapsed into three categories to more succinctly report the students' snacking patterns. These categories were lower frequency ( 1 to 3 times a month), moderate frequency (1 to 4 times a week), and higher frequency ( 5 times a week to 3 or more times a day). The percentage of students who consumed each snack at the higher frequency was calculated separately for the two student samples at each location.

Data from the SFFQ were also used to calculate onand off-campus snack quality indexes (SQIs), following the approach used by Schunk and co-workers [20]. These indexes were based on the energy density and frequency of consumption of each snack listed on the SFFQ. Accordingly, the quality of a snack was based on its approximate nutrient density, that is, the estimated amount of macro and micronutrients relative to the estimated caloric content. Thus, the higher quality (healthier) snacks were those that had a higher nutrient density, that is, they contained greater amounts of protein, fiber, vitamins, and minerals relative to their content of fats, oils, and caloric sweeteners. Conversely, the lower-quality (less healthy) snacks were those that had a lower nutrient density, that is, they contained lower amounts of the macro- and micronutrients relative to their content of fats, oils, and caloric sweeteners. For example, when calculating the SQIs, regular ice cream and regular chips were classified as less healthy snack choices, while lowfat/low-sugar ice cream and low-fat chips were classified as healthier choices. These lower-quality snacks are regarded as less healthy choices because, if consumed frequently, they can contribute to unwanted weight gain [12-15].

Calculation of the SQIs also took into account the frequency of consumption of each snack appearing on the SFFQ. In computing the SQIs, zero points were assigned to each healthier snack that was consumed once a month, one point if consumed 2 to 3 times a month, two points if consumed once a week, three points if consumed twice a week, 4 points if consumed 3 to 4 times a week, 5 points if consumed 5 to 6 times a week, 6 points if consumed once a day, 7 points if consumed twice a day, and 8 points if consumed 3 or more times a day. These point allotments were reversed when scoring the less healthy snacks.

SQI scores were expressed as a percentage of the maximum possible score. The percentage of the maximum possible SQI score was multiplied by the proportion of lowercalorie snacks in the students' diet to differentiate between students who consumed fewer versus more higher-calorie snacks (i.e., snacks low in nutrients relative to their caloric content). The resulting SQI scores were, therefore, reported on a scale ranging from zero to 100 points. Using this scoring system, higher SQI scores are associated with snacking profiles comprised of lower-calorie snacks eaten at higher frequencies and/or higher-calorie snacks eaten at lower frequencies. Snacks that were calorie-free (e.g., bottled water, black coffee, unsweetened tea, and diet soft drinks) were not included on the SFFQ, and snacks that were listed on the SFFQ but that the students never consumed were excluded from the calculation of the SQIs. In summary, the SQIs were intended to serve as rapid assessment measures to characterize the overall healthfulness of the students' snack choices rather than as precise measures of the energy and nutrient content of their snack choices. A similar scoring system was previously used by the authors to characterize the healthfulness of the dietary patterns of adolescents [24]. Moreover, Brunt et al. [29] noted that global measures such as the SQI used in the present study can be more informative for assessing the healthfulness of a diet than methods that focus on a single nutrient, food, or food group.

Wilcoxon-matched pair analysis was performed to identify significant differences between self-efficacy subscale scores on- and off-campus, and the Mann-Whitney independent samples test was used to compare the HRF and NHRF students on their mean SQI and SKT scores, and on their mean perceived barriers and situational self-efficacy subscale scores. Pearson's chisquare was used for comparing distributions of Likert scale responses between HRF and NHRF students. In scoring the 14-item SKT, one point was allotted for each correct and zero points for each incorrect answer.

Spearman correlation analyses were performed to identify associations between the SQI scores and body mass index (BMI), between the SQI scores and SKT scores, and between the SQI scores and the self-efficacy and perceived barriers subscale scores. Statistical significance was $P<0.05$.

\section{Results}

3.1. Participant Characteristics. Completed questionnaires were received from 513 college students, of whom $n=$ $236(46 \%)$ were HRF students and $n=277$ (54\%) were NHRF students. The gender distribution among the HRF students was 68 males and 168 females (29\%:71\%), and among the NHRF students was 124 males and 153 females $(45 \%: 55 \%)$. The race/ethnicity distribution among HRF students was $80 \%$ white, 15\% African-American, 2\% Hispanic, $1 \%$ Asian-American, and 2\% from other groups: among NHRF students, it was $76 \%$ white, $13 \%$ AfricanAmerican, 4\% Hispanic, 2\% Asian-American, and 5\% from other groups. Regarding academic classification for the overall sample, $33 \%$ were first- /second-year students and $67 \%$ were third- / fourth-year students. The mean \pm SD BMI for HRF (NHRF) students was $23.8 \pm 4.2(24.3 \pm 4.4) \mathrm{kg} / \mathrm{m}^{2}$, and the proportion of overweight/obese students for HRF (NHRF) was 30\% (35\%); neither of these differences was statistically significant. 
3.2. Snack Choices and Snack Quality Index (SQI) Scores. The HRF students consumed a median of two daily snacks when off-campus and one when on-campus, while the NHRF students consumed a median of three daily snacks when off-campus and one when on-campus. For the off-campus location, the three snacks consumed at the higher frequency by the greatest proportion of the HRF students were sports drinks (35\%), low-fat milk (34\%), and fresh vegetables (31\%). The corresponding findings for the on-campus location were regular chips (7\%), regular soft drinks (7\%), and sports drinks $(6 \%)$. The snacks consumed at the higher frequency by the greatest proportion of the NHRF students when off-campus were regular cheese $(31 \%)$, sports drinks (29\%), and low-fat milk (29\%), while the corresponding findings for the on-campus location were regular soft drinks $(8 \%)$, sports drinks $(7 \%)$, and regular cheese $(6 \%)$.

Among all students, the 3 lower-calorie snacks consumed at the higher frequency at their off-campus residence by the highest proportion of students were low-fat milk $(32 \%)$, fresh fruit $(32 \%)$, and fresh vegetables $(29 \%)$; the corresponding ranking for on-campus was fresh fruit $(6.8 \%)$, fresh vegetables (5.5\%), and sports drinks (5.5\%). In contrast, the 3 higher-calorie snacks consumed at the lower frequency at their off-campus residence by the highest proportion of students were high-calorie cottage cheese (96\%), high calorie pudding (97\%), and cheese puffs (88\%); the corresponding ranking for on-campus was high-calorie cottage cheese (99\%), high-calorie pudding (97\%), and high-calorie popcorn (97\%).

A self-evaluation of the perceived quality of their snack choices revealed that $5 \%$ of the HRF and $10 \%$ of the NHRF students regarded their snack choices as mostly healthy, while $31 \%$ of the HRF and $22 \%$ of the NHRF students perceived their choices as mostly unhealthy. Additionally, $82 \%$ of the HRF and $81 \%$ of the NHRF students agreed/strongly agreed that their current snack choices could have an influence on their physical health in the years to come, and $16 \%$ of the HRF and $19 \%$ of the NHRF students characterized this influence as mostly unfavorable. A majority (90\%) of the HRF and NHRF students wanted to learn more about healthy snacking, preferably through the internet $(57 \%)$, fliers (49\%), and newspaper articles (36\%).

The mean \pm SD off-campus SQI scores for the HRF and NHRF students were $24.7 \pm 5.6$ points and $23.6 \pm 5.5$ points, respectively (Mann-Whitney chisquare $=6.188, \mathrm{DF}=1, P=$ $0.013)$. There was no significant difference in the mean oncampus SQI scores (21.4 \pm 8.7 points versus $21.2 \pm 9.3$ points) for the HRF and NHRF students, respectively. Additionally, correlations between BMI and the off-campus SQI scores (Spearman $r=-0.097$ ) and between BMI and the oncampus SQI scores (Spearman $r=-0.093$ ) for the sample as a whole were small and not statistically significant.

3.3. Perceived Barriers, Situational Self-Efficacy, and Stage of Change for Healthy Snacking. The mean importance ratings for the barriers to healthy snacking shown in Table 1 indicate that the barriers perceived as most important on- and offcampus for the HRF and NHRF students related to cost, availability, and cravings.

Comparisons of the mean barriers subscale scores for the HRF and NHRF students revealed that significant differences were found only on the internal cues subscale and the awareness subscale, both on- and off-campus, with the NHRF students scoring significantly higher on both subscales.

Regarding situational self-efficacy to choose healthy snacks, the HRF students were least confident when experiencing negative emotions, more confident in positive/social situations, and most confident when accessing healthy snacks was difficult/inconvenient. In contrast, NHRF students were least confident when experiencing negative emotions, more confident when choosing healthy snacks was difficult/inconvenient, and most confident in positive/social situations (Table 2).

Comparisons of the mean self-efficacy subscale scores showed that the HRF students scored significantly higher on the difficult/inconvenient subscale (Mann-Whitney chisquare $=16.879, \mathrm{DF}=1, P<0.001)$ and on the negative/affective subscale (Mann-Whitney chisquare $=6.187$, $\mathrm{DF}=1, P=0.013$ ).

Regarding their readiness to choose healthy snacks, a significantly higher percentage of HRF than NHRF students self-classified in the action stages (75\% versus $65 \%$, resp., $P=0.013)$.

3.4. Knowledge of Healthy Snacks. Table 3 shows the percent of correct answers and the summary statistics for the 14item SKT. The mean \pm SD score for the overall sample was $12.2 \pm 2.0$ points (range 0 to 14 points) out of a possible 14 points, or $87.4 \%$. The majority $(74 \%)$ of the students correctly answered the eight yes/no questions concerning the nutrient characteristics of healthy snacks, and $25 \%$ correctly answered the six multiple-choice questions requiring them to identify the snacks having the nutrient descriptors specified in the stem of the questions. The HRF students had a higher mean SKT score (12.4 \pm 2.0 points) compared to the NHRF students $(12.1 \pm 2.0$ points), although this difference was not statistically significant. The only significant correlation between SQI and SKT scores applied to the HRF students, for whom the off-campus SQI scores showed a small but significant association with their SKT scores (Spearman $r=$ $0.149, P=0.024)$.

An item analysis showed that of the $91.4 \%$ of the students who knew that low in trans fat is a characteristic of healthy snacks, 93\% were also able to identify French fries as the snack with the highest amount of trans fat. However, while $95.2 \%$ of the students knew that high in fiber is a characteristic of healthy snacks, only $42.1 \%$ correctly identified popcorn as a high-fiber snack.

3.5. Relationships between SQI Scores and Psychosocial Correlates. The only significant correlations between the SQI scores and the perceived barriers subscale scores occurred among the HRF students, for which the off-campus SQI 
TABLE 1: Mean importance ratings of barriers to healthy snacking on-campus and off-campus for 513 college students.

\begin{tabular}{|c|c|c|c|c|c|c|}
\hline \multirow{2}{*}{$\begin{array}{l}\text { Subscale or item }{ }^{\text {a }} \text { (Stem: please rate each possible } \\
\text { barrier to eating healthy snacks according to how } \\
\text { important it is to you personally...) }\end{array}$} & \multicolumn{3}{|c|}{ Perceived Importance on-campus } & \multicolumn{3}{|c|}{ Perceived Importance off-campus } \\
\hline & $\begin{array}{c}\text { HRF }^{\mathrm{b}} \\
(N=236)\end{array}$ & $\mathrm{Sig}^{\mathrm{c}}$ & $\begin{array}{c}\text { NHRF }^{\mathrm{b}} \\
(N=277) \\
\end{array}$ & $\begin{array}{c}\text { HRF }^{\mathrm{b}} \\
(N=236)\end{array}$ & $\operatorname{Sig}^{c}$ & $\begin{array}{c}\text { NHRF }^{\mathrm{b}} \\
(N=277)\end{array}$ \\
\hline Practical concerns subscale (mean of 6 items) & $2.6(0.9)$ & ns & $2.6(0.9)$ & $2.5(0.8)$ & ns & $2.7(0.9)$ \\
\hline \multicolumn{7}{|l|}{ Practical concerns individual items ${ }^{\mathrm{d}}$} \\
\hline Too expensive & $3.4(1.5)$ & ns & $3.4(1.6)$ & $3.0(1.3)$ & ns & $3.2(1.4)$ \\
\hline Not readily available & $3.2(1.5)$ & ns & $3.2(1.4)$ & $3.1(1.3)$ & ns & $3.1(1.3)$ \\
\hline Take too long to prepare & $2.6(1.4)$ & ns & $2.7(1.4)$ & $2.9(1.2)$ & ns & $3.0(1.3)$ \\
\hline Difficult to transport & $2.3(1.4)$ & ns & $2.4(1.5)$ & $2.2(1.3)$ & ns & $2.4(1.4)$ \\
\hline My friends do not eat healthy snacks & $2.0(1.3)$ & ns & $2.2(1.3)$ & $2.1(1.3)$ & ns & $2.3(1.3)$ \\
\hline Boy/Girlfriend does not eat healthy snacks & $1.9(1.4)$ & ns & $2.1(1.3)$ & $2.0(1.3)$ & ns & $2.2(1.4)$ \\
\hline Internal cues subscale (mean of 3 items) & $2.4(1.1)$ & $* *$ & $2.7(1.0)$ & $2.5(1.0)$ & $* *$ & $2.7(1.0)$ \\
\hline \multicolumn{7}{|l|}{ Internal cues individual items } \\
\hline Do not satisfy the craving I have & $2.6(1.4)$ & $* *$ & $3.1(1.4)$ & $2.8(1.4)$ & $* *$ & $3.2(1.3)$ \\
\hline Either not sweet enough or salty enough & $2.2(1.2)$ & ns & $2.4(1.2)$ & $2.4(1.2)$ & ns & $2.5(1.2)$ \\
\hline Do not give energy I need & $2.3(1.4)$ & ns & $2.4(1.4)$ & $2.3(1.3)$ & ns & $2.5(1.4)$ \\
\hline Awareness subscale (mean of 2 items) & $2.1(1.3)$ & * & $2.3(1.2)$ & $2.1(1.2)$ & $*$ & $2.3(1.1)$ \\
\hline \multicolumn{7}{|l|}{ Awareness individual items } \\
\hline Do not know how to choose healthy snacks & $2.1(1.4)$ & ns & $2.2(1.3)$ & $2.1(1.3)$ & * & $2.3(1.3)$ \\
\hline Do not know where to find healthy snacks & $2.2(1.4)$ & ns & $2.5(1.4)$ & $2.1(1.3)$ & ns & $2.2(1.2)$ \\
\hline
\end{tabular}

${ }^{\mathrm{a}}$ Each item was rated on a 5-point scale, with 1: least important and 5: most important.

'HRF: health-related fields; NHRF: nonhealth-related fields. Data reported as "mean (standard deviation)."

${ }^{\mathrm{c}}$ Statistical significance for HRF versus NHRF, ns: not significant $(P \geq 0.05)$; $P<0.05 ; * * P<0.01$.

${ }^{\mathrm{d}}$ Items within each subscale are ordered from highest to lowest mean score based on off-campus means for NHRM.

TABLE 2: Mean Ratings on situational self-efficacy subscales for eating healthy snacksfor 513 college undergraduates.

\begin{tabular}{|c|c|c|c|c|c|}
\hline \multirow{2}{*}{$\begin{array}{l}\text { Item or total subscale a (Stem: please rate how confident you are in your ability to } \\
\text { eat a healthy snack under each of the following circumstances) }\end{array}$} & \multicolumn{2}{|c|}{$\operatorname{HRF}^{\mathrm{b}}(N=236)$} & \multirow[t]{2}{*}{$\operatorname{Sig}^{c}$} & \multicolumn{2}{|c|}{$\operatorname{NHRF}^{\mathrm{b}}(N=277)$} \\
\hline & mean & SD & & mean & SD \\
\hline Negative Affect Subscale (mean of 7 items) & 2.9 & 0.9 & $* *$ & 2.6 & 0.9 \\
\hline When I am depressed or down & 2.6 & 1.1 & $* *$ & 2.4 & 1.1 \\
\hline When I have had an argument & 2.9 & 1.1 & $* *$ & 2.4 & 1.1 \\
\hline When I have had a tough day & 2.8 & 1.1 & $* *$ & 2.5 & 1.1 \\
\hline When I am angry & 3.0 & 1.1 & * & 2.7 & 1.2 \\
\hline When I am anxious & 3.1 & 1.2 & $*$ & 2.8 & 1.2 \\
\hline When I feel frustrated & 2.9 & 1.1 & ns & 2.7 & 1.1 \\
\hline When I feel bored & 2.7 & 1.3 & ns & 2.8 & 1.3 \\
\hline Positive/Social Subscale (mean of 4 items) & 3.1 & 1.0 & ns & 3.2 & 1.0 \\
\hline When with friends at party & 2.9 & 1.3 & * & 3.0 & 1.2 \\
\hline At happy celebrations with friends & 3.2 & 1.3 & * & 3.2 & 1.2 \\
\hline While eating out with friends & 3.2 & 1.2 & ns & 3.2 & 1.2 \\
\hline While at picnic/barbeque & 3.1 & 1.2 & ns & 3.1 & 1.2 \\
\hline Difficult/Inconvenient Subscale (mean of 6 items) & 3.2 & 0.8 & $* *$ & 2.9 & 0.9 \\
\hline When less healthy snacks available & 2.8 & 1.1 & ns & 2.7 & 1.1 \\
\hline When I need to prepare myself & 3.5 & 1.3 & $*$ & 3.4 & 1.3 \\
\hline When eating healthy is too much trouble & 2.7 & 1.0 & ns & 2.5 & 1.0 \\
\hline When eating healthy means I prepare & 3.2 & 1.2 & * & 3.1 & 1.2 \\
\hline When substituting unhealthy with healthy is a pain & 2.9 & 1.1 & * & 2.8 & 1.0 \\
\hline When eating less healthy is more convenient & 3.0 & 1.1 & ns & 2.9 & 1.2 \\
\hline
\end{tabular}

${ }^{a}$ Each item was rated on a 5-point scale, with 1: least confident and 5: most confident.

${ }^{b}$ HRF: health-related fields, NHRF: nonhealth-related fields.

'Statistical significance for comparison of HRF and NHRF, ns: not significant $(P \geq 0.05)$; ${ }^{*} P<0.05$; $* * P 0.01$. 
TABLE 3: Frequencies of correct and incorrect responses, and overall summary statistics, from 513 college undergraduates on the snack knowledge test.

\begin{tabular}{|c|c|c|c|c|}
\hline & $\begin{array}{l}\text { Correct } \\
\text { answer }\end{array}$ & $\begin{array}{c}\operatorname{HRF}^{\mathrm{a}}(N=236) \\
\% \text { Correct }\end{array}$ & $\operatorname{Sig}^{\mathrm{b}}$ & $\begin{array}{c}\text { NHRF }^{a}(N=277) \\
\% \text { Correct }\end{array}$ \\
\hline \multicolumn{5}{|l|}{ Part I stem of question: which is a characteristic of a healthy snack? } \\
\hline High in fiber & Yes & 96.4 & ns & 94.3 \\
\hline Low in trans fat & Yes & 92.9 & ns & 90.5 \\
\hline Low in cholesterol & Yes & 97.3 & ns & 93.9 \\
\hline High in calories & No & 97.3 & $*$ & 92.8 \\
\hline Low in vitamins/minerals & No & 96.4 & ns & 94.3 \\
\hline High in saturated fat & No & 97.8 & ns & 95.4 \\
\hline Low in sugar & Yes & 94.2 & $*$ & 87.8 \\
\hline High in salt & No & 98.7 & $*$ & 94.7 \\
\hline \multicolumn{5}{|l|}{ Part II stem of question: which snack is ...? } \\
\hline Lowest in salt (among grapes, corn chips, light cheddar cheese) & grapes & 93.9 & ns & 93.7 \\
\hline Highest in fiber (among French fries, popcorn, cottage cheese) & popcorn & 40.0 & ns & 39.6 \\
\hline Highest in trans fat (among pretzels, French fries, apples) & French fries & 91.7 & ns & 90.3 \\
\hline Lowest in cholesterol (among carrots, cheese pizza, whole milk) & carrots & 94.4 & $*$ & 88.8 \\
\hline Highest in saturated fat (among peaches in syrup, raisin bagel, cheese pizza) & cheese pizza & 75.2 & ns & 73.9 \\
\hline Lowest in calories (among candy bar, potato chips, light yogurt) & light yogurt & 93.9 & ns & 94.4 \\
\hline \multicolumn{5}{|l|}{ Overall Knowledge Test Summary Statistics (Mean \pm SD) } \\
\hline Part I (out of 8 possible points) & & $7.5 \pm 1.4$ & ns & $7.3 \pm 1.6$ \\
\hline Part II (out of 6 possible points) & & $4.9 \pm 1.0$ & ns & $4.8 \pm 1.0$ \\
\hline Total Score (out of 14 possible points) & & $12.4 \pm 2.0$ & ns & $12.1 \pm 2.0$ \\
\hline
\end{tabular}

${ }^{a}$ HRF: Health-related fields, NHRF: Nonhealth-related fields.

bStatistical significance for comparison of HRF and NHRF, ns: not significant $(P \geq 0.05)$; ${ }^{*} P<0.05 ;{ }^{* *} P<0.01$.

scores correlated negatively with the internal cues subscale scores (Spearman $r=-0.246, P<0.001$ ), and with the awareness subscale scores (Spearman $r=-0.172, P=$ 0.011). The off-campus SQI scores for both student samples were significantly positively correlated with the overall selfefficacy scale scores (all three subscales); HRFs Spearman $r=0.362, P<0.001$, NHRFs Spearman $r=0.295, P<$ 0.001 . However, no significant correlations emerged between the on-campus SQI scores and the overall self-efficacy scale scores. Additionally, statistically significant differences emerged between the mean off-campus SQI scores $(20.6 \pm 4.9$ points versus $25.6 \pm 5.2$ points, Mann-Whitney chisquare $=$ 95.798, $\mathrm{DF}=1, P<0.001)$ and between the mean on-campus SQI scores ( $19.0 \pm 7.3$ points versus $22.3 \pm 9.4$ points, MannWhitney chisquare $=24.911$, DF $=1, P<0.001$ ) for the students who self-classified in the preaction or action stages, respectively, regardless of their field of study.

\section{Discussion}

The low mean on- and off-campus SQI scores reported for the HRF and NHRF students suggest unhealthy snacking patterns characterized by frequent consumption of energydense snacks. For example, fruits and vegetables were consumed at the higher frequency by less than one third of the HRF and NHRF students off-campus and by less than $10 \%$ of both samples on-campus, low-fat dairy foods were consumed at the higher frequency by approximately one third of the HRF and NHRF students off-campus and by less than $10 \%$ of both samples on-campus, and wholegrain products were consumed at the higher frequency by less than $10 \%$ of both samples at both locations. Regular consumption of energy-dense snacks by college students has previously been reported $[12-14,29]$. Since such products can add a considerable number of calories to a daily diet [12-14], we hypothesize that the snacking patterns of the students in the present study may have contributed to the high prevalence $(32.2 \%)$ of overweight/obesity reported for our overall sample. Our hypothesis is supported by the findings of an earlier study by Burger and co-workers [7] that examined the relationship between self-selected portion sizes and BMI in a college sample. These authors reported a strong positive correlation between BMI and consumption of large portion sizes for high-calorie foods and snacks. We acknowledge, however, that our self-reported anthropometric and dietary data may contain estimation and recall errors [30]. Additionally, the excess adiposity found in our sample may have been partly attributable to frequent consumption of high-energy meals and a sedentary lifestyle, neither of which was measured in this study.

Despite the low mean SQI scores earned by the HRF and NHRF students, three fourths of the former sample and two-thirds of the latter sample self-classified in the action stages of change for healthy snacking. Additionally, while the 
mean scores on the SKT reported for the two student samples reflect a good understanding of the nutrient characteristics of healthy snacks, the students' low SQI scores suggest a disconnect between acquired nutrition knowledge and its application when making snack choices. Hence, the low SQI scores, the high prevalence of overweight/obesity, and the possibility that some students misclassified themselves in the action stages suggest a need for health promotion programs that offer HRN and NHRN students opportunities to taste, purchase, and prepare healthy snacks. This need is underscored by the findings that approximately $30 \%$ of the HRF and approximately $20 \%$ of the NHRF students regarded their snack choices as mostly unhealthy, and that almost $20 \%$ of the students in both samples acknowledged that their current snack choices could have an unfavorable effect on their long-term health.

Snack preparation and tasting activities should offer college students the opportunity to taste a variety of healthy snacks, with the aim of motivating them to want to invest their limited time and money in purchasing and preparing such snacks. These tasting opportunities should feature palatable snacks that can be safely transported in a backpack and should be made using easy-to-follow recipes, and affordable, familiar ingredients. Emphasis should be placed on fiber-rich foods, given that small percentages of the HRF and NHRF students snacked on fresh fruits, vegetables, and wholegrain foods on- or off-campus. The most popular snack recipes could subsequently be offered to the students on-line, on fliers, and in the student newspaper, since these were the preferred media identified by the students for receiving information about healthy snacking. Our findings suggest that these students would be receptive to such activities, since almost $90 \%$ expressed an interest in learning more about healthy snacking.

Programs focusing on snack purchasing should teach college students how to make healthy snack choices from different kinds of food outlets, including vending machines, convenience stores, and grocery stores. One strategy would be to provide nutrition information at or near the point-ofpurchase, given that Freedman and Connors [31] found that college students made healthier food purchases at on-campus convenience stores when nutrition information was available at the point of purchase. In particular, snack purchasing interventions should teach college students how to identify fiber-rich snack foods, given that half the students incorrectly identified the snack that was highest in fiber on the SKT. The most common response to this test item was cottage cheese rather than popcorn, suggesting that those students who answered this question incorrectly are misinterpreting the lumpy appearance of cottage cheese as an indication that this food possesses a high fiber content. Since highfiber foods can help with weight management [32] and can assist in lowering LDL cholesterol [33], health promotion interventions focusing on healthy snacking should teach these young adults how to identify high-fiber foods and emphasize the potential health benefits of adding more of these foods to their diets.

Since greater proportions of the HRF and NHRF students consumed fresh fruits and vegetables and low-fat/fat-free milk off- campus than on-campus, it would be worthwhile to approach on-campus food vendors with suggestions about making these products more available and affordable, along with smaller packages of such popular snacks as popcorn, chips, cookies, and so forth. Making these products more accessible on-campus could help the students overcome their most important barriers to healthy snacking, that is, availability and cost, while making valuable contributions to their daily calorie and nutrient intakes [10, 32].

Snack tasting, preparation, and purchasing activities could be offered in introductory health and nutrition courses, during guided supermarket tours, at on-campus social gatherings, at student health centers, during athletic and wellness events, and at dining/residence halls. However, the finding that the students felt least confident to choose healthy snacks when they are emotionally upset suggests that affording these young people learning opportunities about healthy snacking may not suffice to produce desirable dietary change. Our findings suggest that interventions are also needed that teach college students techniques for enhancing their self-confidence to choose healthy snacks under unfavorable emotional and environmental circumstances. Regarding the impact of negative emotions on food selection, Locher and co-workers [34] reported that young adults often eat high-calorie foods for comfort when they are depressed, lonely, or bored. If motivational messages are to be a part of these interventions, Wilson [35] recommends that, for greater effectiveness, the following are to be considered: tailoring the message to the cognitive abilities of the audience; making the message relevant to the audience; wording the message clearly and specifically, with no distractions; delivering the message through a medium that allows for reflection and self-pacing rather than one that allows for little audience control; having the message delivered by a credible source; and using a spokesperson that shares characteristics with the audience.

This study has several noteworthy strengths and limitations. A key strength is that, including such psychosocial correlates as perceived barriers, situational self-efficacy, stage of change, and knowledge generates findings that permit nutrition and health educators to tailor interventions to the needs of specific student groups. The rapid assessment nature of the SQI makes its ease of use appealing, but validation of this tool with college samples is needed to enhance its usefulness.

The limitations of this study include the use of a convenience sample that prevents the generalizability of the findings, the use of the SQI as the single indicator of the healthfulness of the students' snacking patterns, the narrow geographic scope, and the self-reported nature of all measures. It is also acknowledged that not all instruments used in the study have undergone rigorous evaluation, and that the students who refused to complete the questionnaire may have differed from the participants on the demographic, behavioral, and psychosocial variables examined; however, the refusal rate was low (approximately one refusal for every ten who completed the survey). If other studies using validated snack frequency questionnaires similar to that used in the present study, probability samples, and a broader 
geographic scope corroborate our findings, future research should focus on developing and evaluating interventions and messages about healthy snacking for college students when spending time on-campus and at home. Previous research suggests that these educational efforts are more likely to produce the desired behavior change, that is, healthy snack selection, if these learning opportunities were tailored to college students in the preaction and action stages of change for healthy snacking [21-23].

\section{Conclusions}

In conclusion, there were few differences in the on and offcampus snacking patterns of the HRF and NHRF students. The most notable difference was the higher proportion of students consuming lower-calorie snacks such as low-fat milk and fresh fruits and vegetables off-campus compared to on-campus. However, at both locations, fruits and vegetables in any form, low-fat dairy foods, and whole grain products were consumed as snacks by small percentages of the students. These findings suggest a need for interactive programs that offer college students opportunities to taste healthy snacks, that teach them how to purchase and prepare such snacks for long-term health promotion, and that enhance their confidence to select these products under challenging emotional and environmental circumstances. Since the overweight/obese students are at risk of developing debilitating chronic diseases $[5,6]$, it is important that they recognize healthier snack options on- and off-campus and understand the unfavorable health implications of consuming high-fat, sugary snacks on a regular basis.

\section{Acknowledgments}

The authors would like to thank the two undergraduates who devoted hours to recruitment and questionnaire distribution, and the 513 students who took the time to complete the questionnaire. They are willing to supply on request any of the instruments used in this study.

\section{References}

[1] Centers for Disease Control and Prevention, "Overweight and obesity, obesity trends: U.S. obesity trends 1985-2004," http:// www.cdc.gov/nccdphp/dnpa/obesity/trend/maps/index.htm.

[2] A. Romero-Corral, V. K. Somers, J. A. Sierra-Johnson et al., "Accuracy of body mass index in diagnosing obesity in the adult general population," International Journal of Obesity, vol. 32, no. 6, pp. 959-966, 2008.

[3] Centers for disease Control and Prevention, "Behavioral risk factor surveillance system," http://apps.nccd.cdc.gov/brfss/ index.asp.

[4] C. Morphew, "Conceptualizing change in the institutional diversity of u.s. colleges and universities," Journal of Higher Education, vol. 80, no. 3, pp. 243-269, 2009.

[5] L. Spencer, "Results of a heart disease risk-factor screening among traditional college students," Journal of American College Health, vol. 50, no. 6, pp. 291-296, 2002.

[6] J. Byles, "Obesity: the new global threat to healthy ageing and longevity," Health Sociology Review, vol. 18, no. 4, pp. 412-422, 2009.
[7] J. A. Skelton, S. R. Cook, and P. Auinger, "Prevalence and trends of severe obesity among us children and adolescents," Academic Pediatrics, vol. 9, no. 5, pp. 322-329, 2009.

[8] J. Shaw, "Epidemiology of childhood type 2 diabetes and obesity," Pediatric Diabetes, vol. 8, supplement 9, pp. S7-S15, 2007.

[9] M. F. Rolland-Cachera, M. Deheeger, M. Maillot, and F. Bellisle, "Early adiposity rebound: causes and consequences for obesity in children and adults," International Journal of Obesity, vol. 30, no. 4, pp. S11-S17, 2006.

[10] United States Department of Health and Human Services, "Healthy people 2010," http://www.healthypeople.gov.

[11] United States Department of Health and Human Services, "The Surgeon General's call to action to prevent and decrease overweight and obesity," http://www.surgeongeneral .gov/topics/obesity/.

[12] T. A. Farley, E. T. Baker, L. Futrell, and J. C. Rice, "The ubiquity of energy-dense snack foods: a national multicity study," American Journal of Public Health, vol. 100, no. 2, pp. 306-311, 2010.

[13] M. C. Nelson and M. Story, "Food environments in university dorms: 20,000 calories per dorm room and counting," American Journal of Preventive Medicine, vol. 36, no. 6, pp. 523-526, 2009.

[14] M. L. Ovaskainen, H. Reinivuo, H. Tapanainen, M. L. Hannila, T. Korhonen, and H. Pakkala, "Snacks as an element of energy intake and food consumption," European Journal of Clinical Nutrition, vol. 60, no. 4, pp. 494-501, 2006.

[15] K. S. Burger, M. Kern, and K. J. Coleman, "Characteristics of self-selected portion size in young adults," Journal of the American Dietetic Association, vol. 107, no. 4, pp. 611-618, 2007.

[16] F. Pineda and B. H. Kleiner, "Management of operations in the snack industry," Management Restaurant News, vol. 28, no. 2/3, pp. 118-126, 2005.

[17] S. N. Zenk and L. M. Powell, "US secondary schools and food outlets," Health and Place, vol. 14, no. 2, pp. 336-346, 2008.

[18] Vending Times Inc, Census of the Industry: 2007 Edition, Vending Times, New York, NY, USA, 2007.

[19] J. O. Prochaska and C. C. Di Clemente, "Transtheoretical therapy: toward a more integrative model of change," Psychotherapy: Theory, Research, and Practice, vol. 19, no. 3, pp. 276-288, 1982.

[20] J. M. Schunk, L. H. McArthur, and C. A. Maahs-Fladung, "Correlates for healthful snacking among middle-income midwestern women," Journal of Nutrition Education and Behavior, vol. 41, no. 4, pp. 274-280, 2009.

[21] S. Ounpuu, D. M. Woolcott, and S. R. Rossi, "Self-efficacy as an intermediate outcome variable in the transtheoretical model: validation of a measurement model for applications to dietary fat reduction," Journal of Nutrition Education and Behavior, vol. 31, no. 1, pp. 16-22, 1999.

[22] E. J. Lea, D. Crawford, and A. Worsley, "Consumers' readiness to eat a plant-based diet," European Journal of Clinical Nutrition, vol. 60, no. 3, pp. 342-351, 2006.

[23] S. J. Chung, S. Hoerr, R. Levine, and G. Coleman, "Processes underlying young women's decisions to eat fruits and vegetables," Journal of Human Nutrition and Dietetics, vol. 19, no. 4, pp. 287-298, 2006.

[24] F. E. Thompson and A. F. Subar, "Dietary assessment methodology," in Nutrition in the Prevention and Treatment of Disease, A. M. Coulston and C. T. Boushey, Eds., chapter 1, Academic Press, San Diego, Calif, USA, 2nd edition, 2008. 
[25] A. Schumann, P. A. Estabrooks, C. R. Nigg, and J. Hill, "Validation of the stages of change with mild, moderate, and strenuous physical activity behavior, intentions, and selfefficacy," International Journal of Sports Medicine, vol. 24, no. 5, pp. 363-365, 2003.

[26] E. A. Dannecker, H. A. Hausenblas, D. P. Connaughton, and T. R. Lovins, "Validation of a stages of exercise change questionnaire," Research Quarterly for Exercise and Sport, vol. 74, no. 3, pp. 236-247, 2003.

[27] J. di Noia and J. O. Prochaska, "Dietary stages of change and decisional balance: a meta-analytic review," American journal of health behavior, vol. 34, no. 5, pp. 618-632, 2010.

[28] A. Schumann, C. Meyer, H. Rumpf, W. Hannöver, U. Hapke, and U. John, "Stage of change transitions and processes of change, decisional balance, and self-efficacy in smokers: a transtheoretical model validation using longitudinal data," Psychology of Addictive Behaviors, vol. 19, no. 1, pp. 3-9, 2005.

[29] A. Brunt, Y. Rhee, and L. Zhong, "Differences in dietary patterns among college students according to body mass index," Journal of American College Health, vol. 56, no. 6, pp. 629-634, 2008.

[30] F. E. Thompson, A. F. Subar, C. C. Brown et al., "Cognitive research enhances accuracy of food frequency questionnaire reports: results of an experimental validation study," Journal of the American Dietetic Association, vol. 102, no. 2, pp. 212-225, 2002.

[31] M. R. Freedman and R. Connors, "Point-of-purchase nutrition information influences food-purchasing behaviors of college students: a pilot study," Journal of the American Dietetic Association, vol. 110, no. 8, pp. 1222-1226, 2010.

[32] R. S. Mozaffarian, J. L. Wiecha, and B. A. Roth, "Impact of an organizational intervention designed to improve snack and beverage quality in YMCA after-school programs," American Journal of Public Health, vol. 100, no. 5, pp. 925-932, 2010.

[33] Z. H. Wei, H. Wang, X. Y. Chen et al., "Time- and dosedependent effect of psyllium on serum lipids in mild-tomoderate hypercholesterolemia: a meta-analysis of controlled clinical trials," European Journal of Clinical Nutrition, vol. 63, no. 7, pp. 821-827, 2009.

[34] J. L. Locher, W. C. Yoels, and D. Maurer, "Comfort foods: an exploratory journey into the social and emotional significance of food," Food and Foodways: History and Culture of Human Nourishment, vol. 13, no. 4, pp. 273-297, 2005.

[35] B. J. Wilson, "Designing media messages about health and nutrition: what strategies are most effective?" Journal of Nutrition Education and Behavior, vol. 39, supplement 1, no. 2, pp. S13-S19, 2007. 


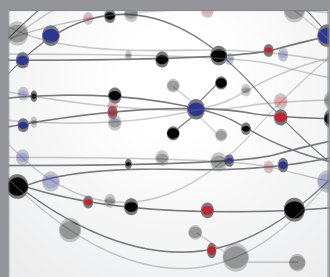

The Scientific World Journal
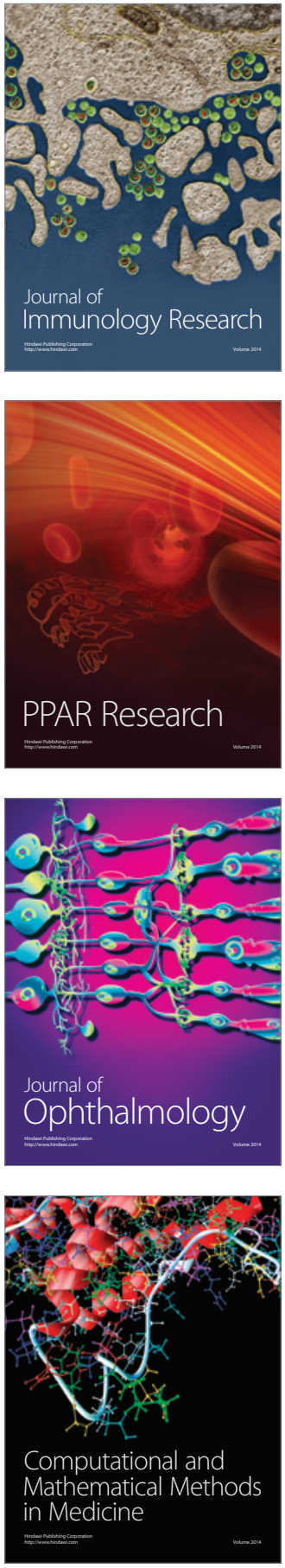

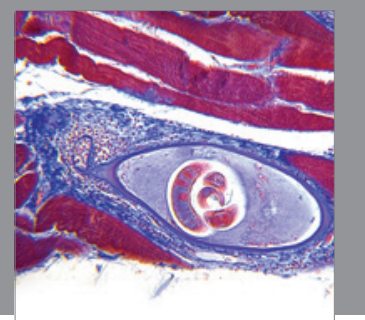

Gastroenterology

Research and Practice
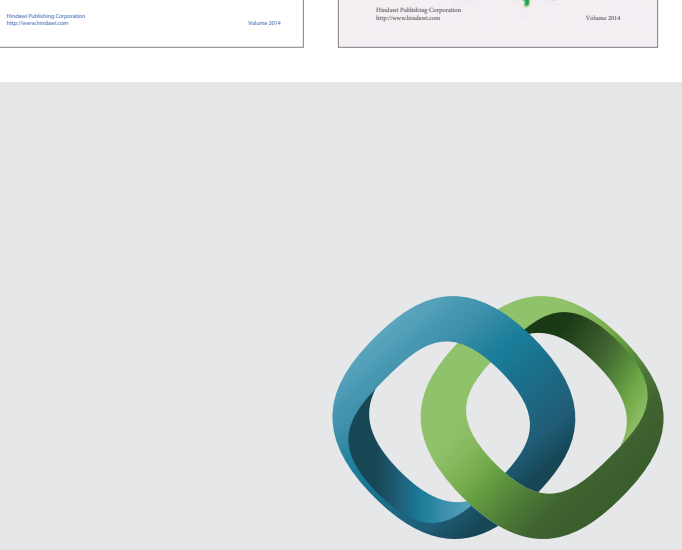

\section{Hindawi}

Submit your manuscripts at

http://www.hindawi.com
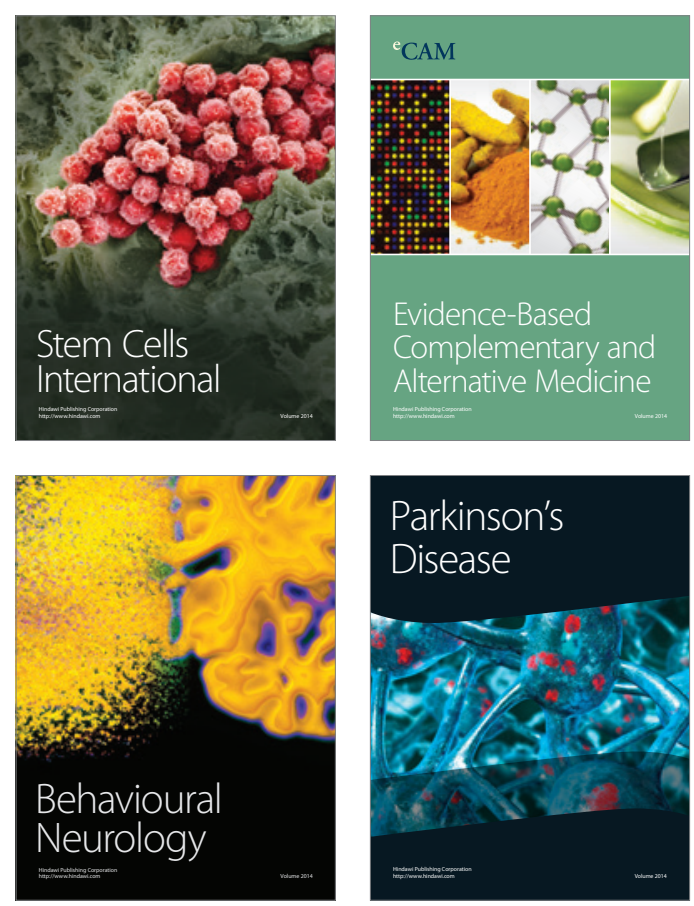

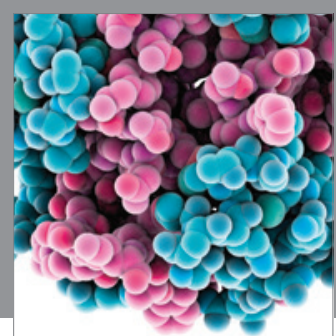

Journal of
Diabetes Research

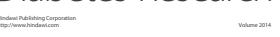

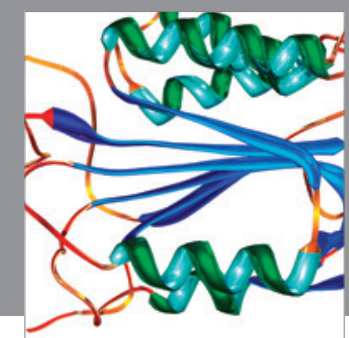

Disease Markers
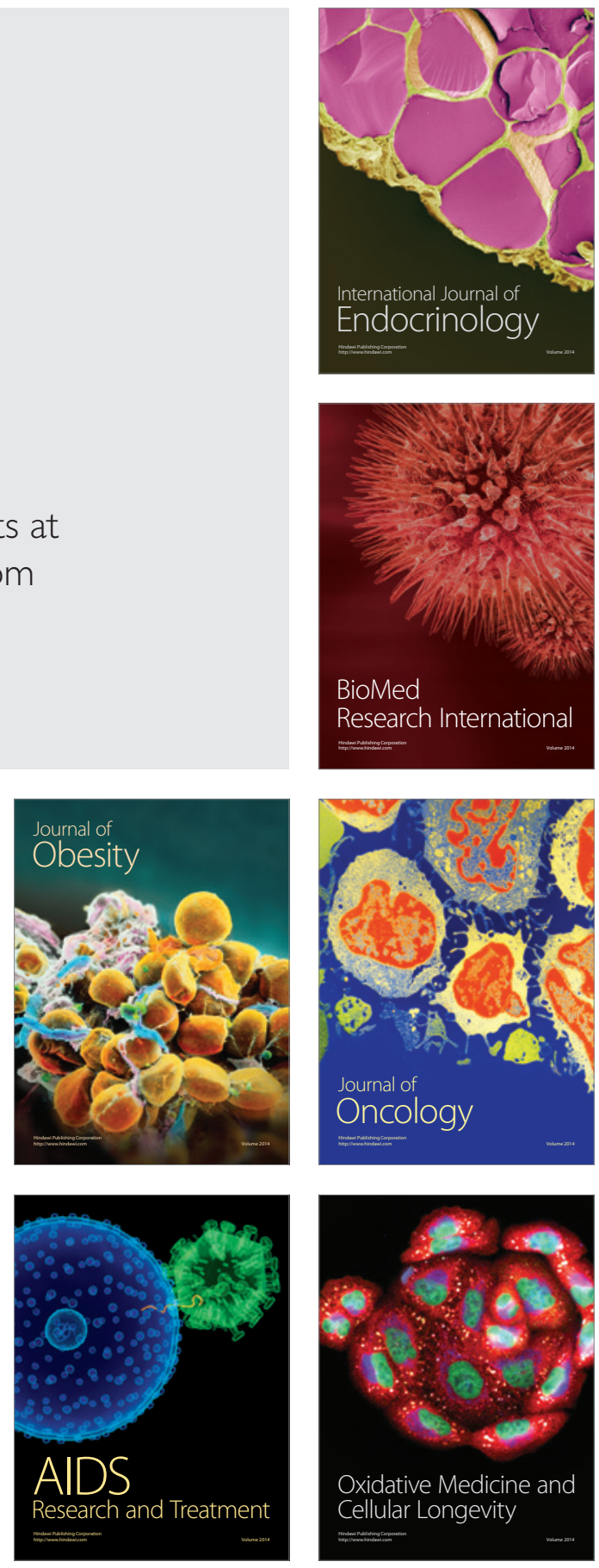